\title{
PENGUKURAN TINGKAT KEPUASAN PENGUNJUNG TERHADAP PANTAI VIO-VIO DAN PANTAI MELAYU DI KOTA BATAM
}

\author{
Anggia Arista ${ }^{1 *}$, Yan Mahesa Damanik ${ }^{2}$ \\ 1,2* Program Studi Teknik Industri Fakultas Teknik Universitas Putera Batam \\ Jl. R Soeprapto, Tembesi, Kota Batam, Kepulauan Riau \\ *e-mail: anggiaarista4@gmail.com
}

\begin{abstract}
Batam is a city located in the Riau archipelago., besides being known as an industrial city, Batam City is also a famous tourist attraction, where one of them is a motorcycle tourism ojek, several beaches frequented by local and national tourists are beaches located in the region barelang namely vio-vio beach and Malay beach. The beauty of nature and the attractiveness of building and beach facilities are needed for the advancement of the beaches in the city of Batam in order to advance and develop coastal tourism. To maintain and maintain the number of beach visitors is needed an effort to maintain the quality of service so that visitor satisfaction can be maintained and improved. The purpose of this study is to determine the level of satisfaction of the end using the servqual method based on five aspects, namely tangible, reliability, responsiveness, assurance, and empathy, and by taking a sample of 130 samples. The results of the study of 130 respondents were for the servqual score, which is the average value of the gab for each dimension. Based on the results of research conducted servqual value of each dimension on the vio-vio beach is tangible $(-1,014)$, reliability ($0,910)$, responsiveness $(-0,969)$ assurance $(-0,967)$, and empathy, namely $(-1,077)$, while for Malay beach are tangible $(-1,005)$, reliability $(0,969)$, responsiveness $(-0,938)$ assurance $(-0,883)$, and empathy $(-0,992)$, and based on servqual score calculation results of the calculation of gab for the five dimensions> -1 which means satisfied, for IPA analysis on the vio-vio beach that needs to be improved is in quadrant I namely the dimensions of reliability, responsiviness and empathy while on the Malay coast is tangible, responsiviness and empathy.
\end{abstract}

Keywords: Level of satisfaction, vio-vio beach, melayu beach, servsqual, IPA

\section{Pendahuluan}

Industri pelayanan jasa merupakan kegiatan yang menitik beratkan pada pelayanan serta menunjang aktivitas industri lainnya yang mampu memberikan pelayanan/jasa kepada konsumen (Wigjosoebroto,2004) dalam (Sutanta,2010:27). Industri pariwisata merupakan salah satu Industri yang bergerak dalam kegiatan menyediakan jasa pada konsumen dimana kepuasan merupakan salah satu indikator terpenting dalam industri ini.

Menurut Undang-Undang Republik Indonesia Nomor 10 (2009) Industri Pariwisata merupakan kumpulan usaha yang menyediakan barang dan/atau jasa bagi pemenuhan kebutuhan wisatawan dan penyelenggaraan pariwisata yang saling terkait dalam rangka menghasilkan barang dan/atau jasa bagi pemenuhan kebutuhan wisatawan dalam penyelenggaraan pariwisata. Usaha pariwisata meliputi tiga belas jenis usaha utama, yaitu: daya tarik wisata, kawasan pariwisata, jasa transportasi wisata, jasa perjalanan wisata, jasa makanan dan minuman, penyediaan akomodasi, penyelenggaraan kegiatan hiburan dan rekreasi, penyelenggaraan pertemuan, perjalanan insentif, konferensi dan pameran, jasa informasi pariwisata, jasa konsultan pariwisata, wisata tirta, serta spa.

Kota Batam merupakan salah satu tujuan pariwisata terbesar di Indonesia, dimana pada tahun 2017 jumlah wisatawan mancanegara yang berkunjung ke Kota Batam mencapai 1.504.275 jiwa (BPS Kepri,2017). Selain wisatawan mancanegara, penduduk yang bermukim di kota Batam pada hari libur banyak yang berkunjung ke objek wisata salah satunya pantai. Kota Batam memiliki banyak pantai 
karena merupakan bagian dari kepulauan riau, dua buah pantai yang paling banyak dikunjungi adalah pantai yang Vio-Vio dan pantai Melayu. Berdasarkan survei yang dilakukan oleh peneliti dari 172 pengunjung objek wisata pantai yang dibagikan menggunakan google form yaitu memilih 5 pantai yang sering dikunjungi di kota Batam maka pantai Melayu menjadi urutan pertama yaitu $66,3 \%$ dan pantai Vio-vio sebesar $65,2 \%$.

Kepuasan wisatawan merupakan hasil dari kualitas layanan yang diberikan oleh pengelola objek wisata yang dapat dilihat dari kesesuaian antara pelayanan atau informasi yang diberikan dengan pelayanan yang diharapkan. Kepuasan wisatawan sebagai konsumen perlu diketahui hal ini berguna untuk keberlanjutan industri pariwisata.

Dengan melihat cukup tingginya minat pengunjung berlibur ke pantai vio- vio dan melayu peneliti melakukan penelitian dengan tujuan untuk mengetahui seberapa besar tingkat kepuasan pengunjung terhadap pantai vio-vio dan melayu berdasakan metode servsqual dan Importance Performance Anaisis (IPA). Hasil penelitian ini dapat dijadikan sebagai masukan kepada pengelola pantai Vio-vo dan melayu untuk dapat meningkatkan kualitas pelayanan

\section{Landasan Teori}

\subsection{Industri Pariwisata}

Menurut Spillane (1987) dalam Arlina dan Purwanti (2013:4), Industri pariwisata mempunyai beberapa sifat khusus, salah satunya yaitu produksi dan konsumsi terjadi pada waktu yang bersamaan. Tanpa wisatawan yang sedang menggunakan jasa wisata itu tidak akan terjadi kegiatan produksi dan konsumsi wisata.

\subsection{Industri Pariwisata Kota Batam}

Menurut BPS Kota Batam (2017:206) Jumlah wisatawan yang datang ke Batam masih didominasi oleh wisatawan dari Singapura dengan $70,67 \%$ dan Malaysia sebanyak $14,19 \%$. Selain itu, wisatawan dari eropa juga datang ke Batam, seperti dari Negara Inggris, Perancis, dan juga dari Amerika Serikat. Pada tahun 2016, jumlah wisatawan yang berkunjung ke Kota Batammengalami penurunan sebesar $7,07 \%$.

\subsection{Industri Pariwista Pantai Melayu dan Vio- Vio}

Pantai melayu rempang adalah pantai yang terletak di desa Rempang Cafe, Kecamatan Galang, kota Batam. Pantai melayu memiliki pasir putih. Tidak terdapat hotel atau penginapan di dekat pantai. Namun, gubuk dan gazebo menyediakan tempat yang cukup untuk beristirahat selama di pantai. Pihak pengelola kawasan pantai Melayu juga menyediakan beragam fasilitas seperti olah raga air (Banana Boat). Permainan ini menggunakan peralatan yang sudah memenuhi standar internasional. Sajian kuliner khas pesisir hasil laut didapatkan dengan mudah dan harganya terjangkau.

Pantai Vio-vio yaitu pantai yang terletak di Pulau Galang yang melewati Jembatan 5 Barelang yang menghubungkan antara Pulau Rempang dengan Pulau Galang. Pantai Vio-Vio memiliki pemandangan hamparan pasir yang berwarna putih bersih. Pantai ini sudah ada beberapa fasilitas pendukung seperti: gazebo yang disewakan dan permainan banana boat yang bakal menguji adrenalin pengunjung.

\subsection{Kualitas Layanan}

Menurut Tjiptono (2005) dalam Hadiyati (2010:83) Kualitas pelayanan adalah keseluruhan ciri-ciri dan karakteristikkarakteristik dari suatu produk atau jasa dalam hal kemampuannya untuk memenuhi kebutuhankebutuhan yang telah ditentukan atau bersifat laten, dengan menekankan pada orientasi pemenuhan harapan pelanggan untuk memperoleh kecocokan untuk pemakaian (fitness for use).

Ada 8 dimensi kualitas (Wijaya, 2018:11), yaitu:

1. Kinerja/performance, yaitu tingkat konsistensi dan kebaikan fungsi-fungsi produk.

2. Keindahan/aesthetics. Estetika berhubungan langsung dengan penampilan wujud produk (misalnya, gaya dan keindahan) serta penampilan fasilitas, peralatan, personalia, dan materi komunikasi yang berkaitan dengan jasa.

3. Kemudahan perawatan dan perbaikan/serviceability. Berkaitan dengan tingkat kemudahan merawat dan memperbaiki produk. 
4. Keunikan/features, yaitu karakteristik produk yang berbeda secara fungsional dari produk- produk sejenis.

5. Reliabilitas. Reliabilitas adalah probabilitas produk atau jasa menjalankan fungsi yang dimaksud dalam jangka waktu tertentu

6. Daya tahan/durability. Didefinisikan sebagai umur manfaat dari fungsi produk.

7. Kualitas kesesuaian/quality of comformance, yaitu ukuran mengenai apakah sebuah produk atau jasa telah memenuhi spesifikasi yang telah ditetapkan.

8. Kegunaan yang sesuai/fitness for use, yaitu kecocokan produk menjalankan fungsi-fungsi sebagaimana yang diiklankan atau dijanjikannya.

\subsection{Service Quality (SERVQUAL)}

Kepuasan konsumen suatu jasa ditentukan oleh tingkat kepentingan konsumen sebelum menggunakan jasa dibandingkan dengan hasil persepsi konsumen terhadap jasa tersebut setelah konsumen merasakan kinerja jasa tersebut (Wijaya, 2018:61). Menurut Tjiptono \& Diana (2003) dalam Wijaya (2018:65) terdapat 5 dimensi kualitas jasa dalam menerapkan konsep kesenjangan yang disebut service quality, yaitu:

1. Keandalan (reliability). Keandalan adalah kemampuan memberikan pelayanan yang dijanjikan dengan segera, akurat, dan memuaskan.

2. Ketanggapan atau kepedulian (responsiveness). Ketanggapan atau kepedulian adalah keinginan para staf untuk membantu para pelanggan dan memberikan pelayanan dengan tanggap dan peduli terhadap keluhan atau harapan pelanggan.

3. Jaminan kepastian (assurance). Jaminan kepastian adalah jaminan yang diberikan sehingga memberikan rasa aman dari bahaya, resiko, atau keraguan dan kepastian mencakup pengetahuan, kesopanan, dan sikap dapat dipercaya yang dimiliki staf.

4. Perhatian (emphaty). Perhatian adalah sifat dan kemampuan untuk memberikan perhatian penuh kepada pelanggan, kemudahan dalam melakukan kontak, komu-nikasi yang baik, dan memahami kebutuhan pelanggan secara individual.
5. Berwujud (tangibles). Berwujud adalah wujud kenyataan secara fisik yang meliputi fasilitas, peralatan, pegawai, dan sarana informasi atau komunikasi.

Konsep SERVQUAL digunakan untuk menghitung gap antara persepsi atau yang dirasakan pelanggan terhadap jasa yang dikurangi dengan nilai ekspektasi atau harapan pelanggan(Wijaya, 2018:62). Berikut adalah persamaannya:

$\mathrm{Q}=\mathrm{P}-\mathrm{E}$

Keterangan:

$Q \quad=$ Kualitas layanan

$P \quad=$ Perceived service atau persepsi pelanggan atau layanan yang diterima/dirasakan pelanggan

$E=$ Expected service atau harapan pelanggan terhadap layanan.

\subsection{Importance Performance Analysis (IPA)}

Analisis ini diperkenalkan oleh Martilla dan James (Setyaningsih, 2013:139) yang digunakan dalam pemasaran untuk mengidentifikasi laju produk tertentu atau atribut pelayanan, berdasar pada tingkat kepentingan dan dampaknya bagi performa perusahaan secara keseluruhan. Dengan menggunakan matriks ini, manajemen dapat memiliki gambaran ke dalam terhadap atributatribut yang dikehendaki untuk segera dilakukan perbaikan, dan dapat dibandingkan dengan atribut-atribut yang boros dalam penggunaan sumber daya.

\section{Metode Penelitian}

\subsection{Desain Penelitian}

Penelitian ini menggunakan pendekatan kuantitatif dengan metode survei. metode survei pada peenelitian ini menggunakan data primer. Data primer diperoleh dengan menyebarkan kuesioner mengenai kualitas jasa pantai vio-vio dan melayu. Adapun diagram alir penelitian ini adalah sebagai berikut: 

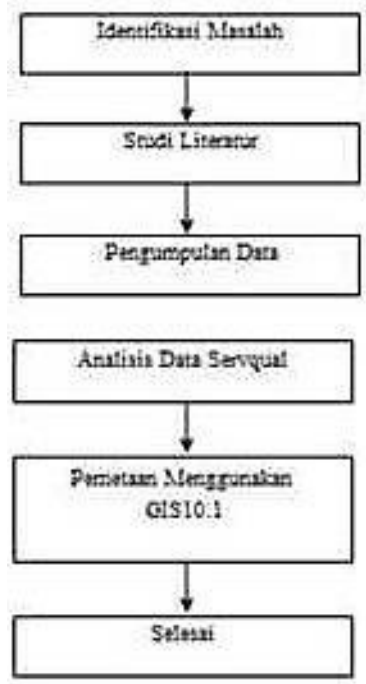

Gambar 3.1 Desain Penelitian

\subsection{Populasi dan Sampel}

Populasi yang digunakan dalam penelitian ini adalah pengunjung objek wisata pantai vio-vio dan melayu. Adapun sampel yang akan digunakan pada penelitian ini adalah wisatawan yang berkunjung pada objek wisata pantai vio-vio dan melayu. Jumlah sampel yang akan dikumpulkan sebanyak 130 wisatawan. Dalam melakukan pemilihan sampel peneliti menggunakan teknik proportional random sampling yaitu pengunjung yang mengisi kuesioner adalah pengunjung yang berada pada saat pembagian kuesioner yang diambil secara random.

\subsection{Teknik Pengumpulan Data}

Data yang akan digunakan yaitu data primer. Data primer didapatkan dari penyebaran kuesioner penelitian yang terdiri dari pertanyaan berkenaan dengan masalah yang diteliti

\subsection{Metode Analisis Data}

Untuk mengetahui variabel-variabel yang diteliti, dilakukan uji validitas dan uji reliabilitas untuk mendapatkan keabsahan pernyataan atau data yang diteliti. Adapun teknik analisis data yang akan digunakan dalam penelitian ini adalah:

1. Melakukan survei pendahuluan untuk mengetahui pantai yang paling sering dikunjungi oleh wisatawan

2. Analisis data dengan menggunakan metode Servsqual, metode ini digunakan untuk menghitung gap antara persepsi terhadap jasa yang dikurangi dengan nilai ekspektasi atau harapan pelanggan.

3. melakukan analisis dengan menggunakan metode Importance Performance Analysis (IPA).

\section{Hasil dan Pembahsan}

\subsection{Hasil Penelitian}

\subsubsection{Profil Responden}

Responden dalam penelitian ini adalah pengunjung yang telah mengunjungi pantai pantai Vio-Vio dan pantai Melayu sebanyak 130 responden. Profil responden ini meliputi karakteristik jenis kelamin, usia, dan pendidikan terakhir.

Tabel 4.1 Karakteristik Responden

\begin{tabular}{lc}
\hline $\begin{array}{l}\text { KARAKTERISTIK } \\
\text { RESPONDEN }\end{array}$ & JUMLAH \\
\hline 1. Jenis Kelamin & \\
Laki-laki & 46 \\
Perempuan & 84 \\
2. Umur & \\
< 17 tahun & 3 \\
18-23 tahun & 67 \\
24-29 tahun & 40 \\
30-35 tahun & 13 \\
36-41 tahun & 7 \\
> 42 tahun & 0 \\
Pendidikan & \\
SD & 2 \\
SLTP & 2 \\
SMA & 110 \\
Diploma (D3) & 2 \\
Sarjana (S1) & 12 \\
Magister (S2) & 2 \\
\hline
\end{tabular}

Sumber: Pengolahan Data

\subsubsection{Hasil Analisis Servqual (Service Quality)}

Analisis servqual digunakan untuk mengetahui tingkat kepuasan pengunjung terhadap dimensi kualitas pelayanan pariwisata pantai di kota Batam yaitu pantai vio-vio, pantai mirota dan pantai melayu.

Tabel berikut ini menunjukkan nilai total tiap atribut dan rata-rata kuesioner presepsi dan harapan untuk setiap pariwisata pantai.

\section{Pantai Vio-Vio}

Hasil Kuesioner yang dibagikan kepada 130 pengunjung Pantai Vio-vio kemudian diolah menggunakan servqual dapat dilihat pada tabel 4.2 berikut ini 
Tabel 4.2. Skor Total dan Rata-Rata pernyataan kuesioner presepsi dan harapan Pantai Vio-vio

\begin{tabular}{|c|c|c|c|c|}
\hline $\begin{array}{l}\text { Atrib } \\
\text { ut }\end{array}$ & Dimensi & $\begin{array}{c}\text { Pernyat } \\
\text { aan }\end{array}$ & $\begin{array}{l}\text { Rata- } \\
\text { rata } \\
\text { prese } \\
\text { psi }\end{array}$ & $\begin{array}{c}\text { Rata- } \\
\text { rata } \\
\text { Harap } \\
\text { an }\end{array}$ \\
\hline 1 & \multirow{11}{*}{$\begin{array}{c}\mathrm{x} 1 \\
\text { (tangibel) }\end{array}$} & 1 & 3,60 & 4,15 \\
\hline 2 & & 2 & 3,93 & 4,24 \\
\hline 3 & & 3 & 3,19 & 4,18 \\
\hline 4 & & 4 & 3,45 & 4,37 \\
\hline 5 & & 5 & 2,95 & 4,13 \\
\hline 6 & & 6 & 2,24 & 4,12 \\
\hline 7 & & 7 & 2,44 & 4,21 \\
\hline 8 & & 8 & 3,52 & 4,27 \\
\hline 9 & & 9 & 3,28 & 4,18 \\
\hline 10 & & 10 & 3,62 & 4,21 \\
\hline 11 & & 11 & 2,88 & 4,22 \\
\hline 12 & \multirow{4}{*}{$\begin{array}{c}\mathrm{x} 2 \\
\text { (reliability) }\end{array}$} & 12 & 3,19 & 4,20 \\
\hline 13 & & 13 & 3,22 & 4,38 \\
\hline 14 & & 14 & 3,10 & 4,27 \\
\hline 15 & & 15 & 3,68 & 4,20 \\
\hline 16 & \multirow{3}{*}{$\begin{array}{c}\mathrm{x} 3 \\
\text { (responsive } \\
\text { ness) }\end{array}$} & 16 & 3,18 & 4,32 \\
\hline 17 & & 17 & 3,19 & 4,28 \\
\hline 18 & & 18 & 3,31 & 4,32 \\
\hline 19 & \multirow{4}{*}{$\begin{array}{c}\mathrm{x} 4 \\
\text { (assurance) }\end{array}$} & 19 & 3,68 & 4,18 \\
\hline 20 & & 20 & 3,22 & 4,22 \\
\hline 21 & & 21 & 3,27 & 4,28 \\
\hline 22 & & 22 & 3,05 & 4,18 \\
\hline 23 & \multirow{3}{*}{$\begin{array}{c}\mathrm{x} 5 \\
\text { (emphaty) }\end{array}$} & 23 & 3,18 & 4,26 \\
\hline 24 & & 24 & 3,38 & 4,23 \\
\hline 25 & & 25 & 3,32 & 4,30 \\
\hline
\end{tabular}

Sedangkan untuk nilai gab setiap pernyataan pada kelima dimensi servqual dapat dilihat pada Tabel 4.2 berikut ini:

Tabel 4.3. Perhitungan Tingkat Kepuasan Konsumen Per Atribut Pantai Vio-Vio

\begin{tabular}{cccccc}
\hline Dimensi & Butir & $\begin{array}{c}\overline{\boldsymbol{X}} \text { prese } \\
\text { psi }\end{array}$ & $\begin{array}{c}\overline{\mathbf{X}} \text { hara } \\
\text { pan }\end{array}$ & Gap & $\begin{array}{c}\text { kateg } \\
\text { ori }\end{array}$ \\
\hline & 1 & 3,60 & 4,15 & $\begin{array}{c}- \\
0,55\end{array}$ & puas \\
\cline { 2 - 6 } & 2 & 3,93 & 4,24 & $\begin{array}{c}- \\
0,31\end{array}$ & puas \\
\cline { 2 - 6 } x1 & 3 & 3,19 & 4,18 & $\begin{array}{c}- \\
0,99\end{array}$ & puas \\
\cline { 2 - 6 } (tangibel) & 4 & 3,45 & 4,37 & $\begin{array}{c}- \\
0,92\end{array}$ & puas \\
\cline { 2 - 6 } & 5 & 2,95 & 4,13 & $\begin{array}{c}- \\
1,18\end{array}$ & $\begin{array}{c}\text { tidak } \\
\text { puas }\end{array}$ \\
\cline { 2 - 6 } & 6 & 2,24 & 4,12 & $\begin{array}{c}- \\
1,88\end{array}$ & $\begin{array}{c}\text { tidak } \\
\text { puas }\end{array}$ \\
\cline { 2 - 6 } & 7 & 2,44 & 4,21 & $\begin{array}{c}- \\
1,77\end{array}$ & $\begin{array}{c}\text { tidak } \\
\text { puas }\end{array}$ \\
\hline
\end{tabular}

\begin{tabular}{|c|c|c|c|c|c|}
\hline & 8 & 3,52 & 4,27 & $\begin{array}{c}- \\
0,75 \\
\end{array}$ & puas \\
\hline & 9 & 3,28 & 4,18 & $\begin{array}{c}- \\
0,90\end{array}$ & puas \\
\hline & 10 & 3,62 & 4,21 & $\begin{array}{c}- \\
0,58 \\
\end{array}$ & puas \\
\hline & 11 & 2,88 & 4,22 & $\begin{array}{c}- \\
1,34 \\
\end{array}$ & puas \\
\hline \multirow{4}{*}{$\begin{array}{c}\mathrm{x} 2 \\
\text { (reliabilit } \\
y)\end{array}$} & 12 & 3,19 & 4,20 & $\begin{array}{c}- \\
1,01\end{array}$ & $\begin{array}{l}\text { tidak } \\
\text { puas }\end{array}$ \\
\hline & 13 & 3,22 & 4,38 & $\begin{array}{c}- \\
1,16 \\
\end{array}$ & $\begin{array}{l}\text { tidak } \\
\text { puas }\end{array}$ \\
\hline & 14 & 3,10 & 4,27 & $\begin{array}{c}- \\
1,17\end{array}$ & $\begin{array}{l}\text { tidak } \\
\text { puas }\end{array}$ \\
\hline & 15 & 3,68 & 4,20 & $\begin{array}{c}- \\
0,52 \\
\end{array}$ & puas \\
\hline \multirow{3}{*}{$\begin{array}{c}\mathrm{x3} \\
\text { (responsi } \\
\text { veness) }\end{array}$} & 16 & 3,18 & 4,32 & $\begin{array}{c}- \\
1,14 \\
\end{array}$ & $\begin{array}{l}\text { tidak } \\
\text { puas } \\
\end{array}$ \\
\hline & 17 & 3,19 & 4,28 & $\begin{array}{c}- \\
1,09 \\
\end{array}$ & $\begin{array}{l}\text { tidak } \\
\text { puas }\end{array}$ \\
\hline & 18 & 3,31 & 4,32 & $\begin{array}{c}- \\
1,01\end{array}$ & $\begin{array}{l}\text { tidak } \\
\text { puas }\end{array}$ \\
\hline \multirow{4}{*}{$\begin{array}{c}\mathrm{x} 4 \\
(\text { assuranc } \\
\text { e) }\end{array}$} & 19 & 3,68 & 4,18 & $\begin{array}{c}- \\
0,50\end{array}$ & puas \\
\hline & 20 & 3,22 & 4,22 & $\begin{array}{c}- \\
1,00\end{array}$ & $\begin{array}{l}\text { tidak } \\
\text { puas }\end{array}$ \\
\hline & 21 & 3,27 & 4,28 & $\begin{array}{c}- \\
1,01\end{array}$ & $\begin{array}{l}\text { tidak } \\
\text { puas }\end{array}$ \\
\hline & 22 & 3,05 & 4,18 & $\begin{array}{c}- \\
1,13\end{array}$ & $\begin{array}{l}\text { Tidak } \\
\text { puas }\end{array}$ \\
\hline \multirow{3}{*}{$\begin{array}{c}\mathrm{x5} \\
(\text { emphaty } \\
\text { ) }\end{array}$} & 23 & 3,18 & 4,26 & $\begin{array}{c}- \\
1,08\end{array}$ & $\begin{array}{l}\text { tidak } \\
\text { puas }\end{array}$ \\
\hline & 24 & 3,38 & 4,23 & $\begin{array}{c}- \\
0,85\end{array}$ & puas \\
\hline & 25 & 3,32 & 4,30 & $\begin{array}{c}- \\
0,98\end{array}$ & puas \\
\hline
\end{tabular}

Tabel 4.4 berikut menunjukkan nilai gap (servqual) antara dimensi kualitas pelayanan kuesioner presepsi dengan kuesioner harapan pada pantai vio-vio.

Tabel 4.4 Perhitungan Tingkat Kepuasan Konsumen Per Dimensi pantai Vio-Vio

\begin{tabular}{ccccc}
\hline Dimensi & $\begin{array}{c}\overline{\boldsymbol{X}} \\
\text { Persepsi }\end{array}$ & $\overline{\mathbf{X}}$ harapan & gap & kategori \\
\hline $\mathrm{x} 1$ (tangibel) & 3,192 & 4,206 & $\begin{array}{c}- \\
1,014\end{array}$ & $\begin{array}{c}\text { Tidak } \\
\text { puas }\end{array}$ \\
\hline $\mathrm{x} 2$ (reliability) & 3,304 & 4,213 & $\begin{array}{c}- \\
0,910\end{array}$ & puas \\
\hline $\begin{array}{c}\text { x3 } \\
\text { (responsiveness) }\end{array}$ & 3,295 & 4,264 & $\begin{array}{c}- \\
0,969\end{array}$ & puas \\
\hline x4 (assurance) & 3,296 & 4,263 & $\begin{array}{c}- \\
0,967\end{array}$ & puas \\
\hline x5 (emphaty) & 3,228 & 4,305 & $\begin{array}{c}- \\
1,077\end{array}$ & Tidak \\
\hline Sumber: Pengolahan Data & & &
\end{tabular}

Sumber: Pengolahan Data

Tingkat Kualitas pelayanan di Pantai Vio-vio 
Berdasarkan tabel 4.4 dapat diketahui bahwa dimensi yang perlu ditingkatkan lagi kualitas pelayanannya adalah dimensi tangible, reliability, responsiveness, assurance dan empahaty. Dimensi Tangible memiliki empat aspek pelayanan yang perlu ditingkatkan lagi kualitasnya yaitu:

1. Pernyataan 5: Sarana dan prasarana transportasi menuju kawasan wisata

2. Pernyataan 6: Sarana komunikasi (sinyal Telepon Seluler)

3. Pernyataan 7: Kondisi srana pendukug komuikasi (stop kontak untuk pengecaan telepon seluler dan laptop

4. Pernyataan 11 : identitas karyawan (berupa seragam dan identitas lainnya)

Dimensi Reliability memiliki tiga aspek pelayanan yang perlu untuk ditingkatkan lagi kualitasnya, yaitu:

1. Pernyataan 12: Kejujuran Karyawan

2. Pernyataan 13: Keramahan, kesopanan karyawan

3. Pernyataan 14 : Kesigapan karyawan dalam melayani dan membantu wisatawan.

Dimensi responsiveness memiliki tiga aspek pelayanan yang perlu untuk ditingkatkan lagi kualitasnya, yaitu:

1. Pernyataan 16: Kecepatan dan ketangguhan dalam menangani keluhan wisatawan

2. Pernyataan 17: Kesesuaian jasa yang diberikan dengan yang dipromosikan

3. Pernyataan 18: Kesesuaian waktu pelayanan dengan jadwal yang ditetapkan

Dimensi assurance memiliki tiga aspek pelayanan yang perlu untuk ditingkatkan lagi kualitasnya, yaitu:

1. Pernyataan 20: Jaminan keselamatan dalam menggunakan wahana yang disediakan

2. Pernyataan 21: Pelayanan dilakukan sesuai dengan prosedur

3. Pernyataan 22: Pemesanan dengan penuh garansi (pemesanan tempat berkumpul/gazebo)

Dimensi assurance memiliki satu aspek pelayanan yang perlu untuk ditingkatkan lagi kualitasnya, yaitu: Pernyataan 23: Keadilan dalam memberikan pelayanan

Berdasarkan nilai skor servsqual untuk kelima dimensi didapatkan hasil dimana nilai Hasil dari penelitian dari 130 responden adalah untuk skor servqual yaitu nilai rata-rata gab tiap dimensi pada pantai vio-vio adalah tangible $(-1,014)$, reliability $(-0,910)$, responsiveness $(-0,969)$ assurance $(-0,967)$, dan empathy yaitu $(-1,077)$, dan berdasarkan perhitungan skor servqual hasil perhitungan gab untuk kelima dimensi yaitu selisih antara kenyataan dan harapan > -1 yang berarti puas dimana dimensi reliability, responsiveness dan assurance dalam kategori puas sedangkan dimensi tangible dan empathy dalam kategori tidak puas dan perlu ditingkatkan.

\section{Pantai Melayu}

Hasil Kuesioner yang dibagikan kepada 130 pengunjung Pantai Vio-vio kemudian diolah menggunakan servqual didapatkan nilai total pernyataan penilaian dari kelima dimensi servqual dapat dilihat pada tabel 4.2 berikut ini

Tabel 4.5. Skor Total dan Rata-Rata pernyataan Kuesioner presepsi dan harapan Pantai Melayu

\begin{tabular}{|c|c|c|c|}
\hline Dimensi & atribut & $\begin{array}{c}\bar{X} \\
\text { presepsi }\end{array}$ & $\begin{array}{c}\bar{X} \\
\text { Harapan }\end{array}$ \\
\hline \multirow{11}{*}{ x1 (tangibel) } & 1 & 3,48 & 4,23 \\
\hline & 2 & 3,53 & 4,28 \\
\hline & 3 & 3,18 & 4,40 \\
\hline & 4 & 3,30 & 4,17 \\
\hline & 5 & 3,33 & 4,22 \\
\hline & 6 & 2,74 & 4,22 \\
\hline & 7 & 2,77 & 4,27 \\
\hline & 8 & 3,54 & 4,09 \\
\hline & 9 & 3,34 & 4,22 \\
\hline & 10 & 3,48 & 4,32 \\
\hline & 11 & 2,90 & 4,21 \\
\hline \multirow{4}{*}{ x2 (reliability) } & 12 & 3,21 & 4,15 \\
\hline & 13 & 3,26 & 4,22 \\
\hline & 14 & 3,22 & 4,20 \\
\hline & 15 & 3,58 & 4,23 \\
\hline \multirow{3}{*}{$\begin{array}{c}\mathrm{x} 3 \\
\text { (responsiveness) }\end{array}$} & 16 & 3,21 & 4,25 \\
\hline & 17 & 3,25 & 4,26 \\
\hline & 18 & 3,34 & 4,26 \\
\hline \multirow{4}{*}{ x4 (assurance) } & 19 & 3,56 & 4,26 \\
\hline & 20 & 3,27 & 4,32 \\
\hline & 21 & 3,32 & 4,32 \\
\hline & 22 & 3,28 & 4,40 \\
\hline \multirow{3}{*}{ x5 (emphaty) } & 23 & 3,27 & 4,27 \\
\hline & 24 & 3,33 & 4,26 \\
\hline & 25 & 3,35 & 4,24 \\
\hline
\end{tabular}

Sumber: Pengolahan Data

Tabel 4.6 berikut ini menunjukkan nilai gap (servqual) antara atribut kuesioner presepsi dengan atribut kuesioner harapan.

Tabel 4.6 Perhitungan Tingkat Kepuasan Konsumen pernyataan pantai Melayu 


\begin{tabular}{|c|c|c|c|c|c|}
\hline Dimensi & $\begin{array}{l}\text { atri } \\
\text { but }\end{array}$ & $\begin{array}{c}\bar{X} \\
\text { presep } \\
\text { si }\end{array}$ & $\begin{array}{c}\overline{\bar{X}} \\
\text { harap } \\
\text { an }\end{array}$ & Gap & $\begin{array}{c}\text { Kategor } \\
\quad i\end{array}$ \\
\hline \multirow{11}{*}{$\begin{array}{c}\mathbf{x 1} \\
\text { (tangibel) }\end{array}$} & 1 & 3,48 & 4,23 & $-0,75$ & puas \\
\hline & 2 & 3,53 & 4,28 & $-0,75$ & puas \\
\hline & 3 & 3,18 & 4,40 & $-1,22$ & $\begin{array}{l}\text { tidak } \\
\text { puas }\end{array}$ \\
\hline & 4 & 3,30 & 4,17 & $-0,87$ & puas \\
\hline & 5 & 3,33 & 4,22 & $-0,89$ & puas \\
\hline & 6 & 2,74 & 4,22 & $-1,48$ & $\begin{array}{l}\text { tidak } \\
\text { puas }\end{array}$ \\
\hline & 7 & 2,77 & 4,27 & $-1,50$ & $\begin{array}{l}\text { tidak } \\
\text { puas }\end{array}$ \\
\hline & 8 & 3,54 & 4,09 & $-0,55$ & puas \\
\hline & 9 & 3,34 & 4,22 & $-0,88$ & puas \\
\hline & 10 & 3,48 & 4,32 & $-0,84$ & puas \\
\hline & 11 & 2,90 & 4,21 & $-1,31$ & $\begin{array}{l}\text { tidak } \\
\text { puas }\end{array}$ \\
\hline \multirow{4}{*}{$\begin{array}{c}\mathbf{x 2} \\
\text { (reliability) }\end{array}$} & 12 & 3,21 & 4,15 & $-0,95$ & puas \\
\hline & 13 & 3,26 & 4,22 & $-0,96$ & puas \\
\hline & 14 & 3,22 & 4,20 & $-0,98$ & puas \\
\hline & 15 & 3,58 & 4,23 & $-0,65$ & puas \\
\hline \multirow{3}{*}{$\begin{array}{c}\mathrm{x} 3 \\
\text { (responsive } \\
\text { ness) }\end{array}$} & 16 & 3,21 & 4,25 & $-1,04$ & $\begin{array}{l}\text { tidak } \\
\text { puas }\end{array}$ \\
\hline & 17 & 3,25 & 4,26 & $-1,02$ & $\begin{array}{l}\text { tidak } \\
\text { puas }\end{array}$ \\
\hline & 18 & 3,34 & 4,26 & $-0,92$ & puas \\
\hline \multirow{4}{*}{$\begin{array}{c}\mathrm{x} 4 \\
\text { (assurance) }\end{array}$} & 19 & 3,56 & 4,26 & $-0,70$ & puas \\
\hline & 20 & 3,27 & 4,32 & $-1,05$ & $\begin{array}{l}\text { tidak } \\
\text { puas }\end{array}$ \\
\hline & 21 & 3,32 & 4,32 & $-1,01$ & $\begin{array}{l}\text { tidak } \\
\text { puas }\end{array}$ \\
\hline & 22 & 3,28 & 4,40 & $-1,12$ & $\begin{array}{l}\text { tidak } \\
\text { puas }\end{array}$ \\
\hline \multirow{3}{*}{$\begin{array}{c}\mathrm{x5} \\
\text { (emphaty) }\end{array}$} & 23 & 3,27 & 4,27 & $-1,00$ & $\begin{array}{l}\text { tidak } \\
\text { puas }\end{array}$ \\
\hline & 24 & 3,33 & 4,26 & $-0,93$ & puas \\
\hline & 25 & 3,35 & 4,24 & $-0,88$ & puas \\
\hline
\end{tabular}

Sumber: Pengolahan Data

Tabel 4.5 berikut ini menunjukkan nilai gap (servqual) antara dimensi kualitas pelayanan kuesioner ekspektasi dengan kuesioner persepsi.

Tabel 4.7. Perhitungan Tingkat Kepuasan Konsumen Per Dimensi pantai melayu

\begin{tabular}{|c|c|c|c|c|}
\hline Dimensi & $\begin{array}{c}\bar{X} \\
\text { perseps } \\
\quad i\end{array}$ & $\begin{array}{c}\bar{X} \\
\text { harapa } \\
n\end{array}$ & gap & $\begin{array}{c}\text { kategor } \\
i\end{array}$ \\
\hline $\mathrm{x} 1$ (tangibel) & 3,24 & 4,24 & $\begin{array}{c}- \\
1,00 \\
5\end{array}$ & $\begin{array}{l}\text { Tidak } \\
\text { puas }\end{array}$ \\
\hline x2 (reliability) & 3,36 & 4,33 & $\begin{array}{c}- \\
0,96 \\
9\end{array}$ & puas \\
\hline $\begin{array}{c}\mathrm{x} 3 \\
\text { (responsivenes } \\
s)\end{array}$ & 3,32 & 4,26 & $\begin{array}{c}- \\
0,93 \\
8\end{array}$ & puas \\
\hline x4 (assurance) & 3,32 & 4,20 & $\begin{array}{c}- \\
0,88 \\
3\end{array}$ & puas \\
\hline
\end{tabular}

\begin{tabular}{ccccc}
\hline x5 (emphaty) & 3,26 & 4,26 & $\begin{array}{c}- \\
0,99\end{array}$ & puas \\
& & & 2 & \\
\hline Sumber: Pengolahan Data
\end{tabular}

Sumber: Pengolahan Data

\section{Tingkat Kualitas pelayanan di Pantai Melayu}

Berdasarkan tabel 4.7 dapat diketahui bahwa dimensi yang perlu ditingkatkan lagi kualitas pelayanannya adalah dimensi tangible, responsiveness, assurance dan empahaty. Dimensi Tangible memiliki empat aspek pelayanan yang perlu ditingkatkan lagi kualitasnya yaitu:

1. Pernyataan 3: Kondisi Sarana Untuk Informasi (Pusat Informasi dan media informasi)

2. Pernyataan 6: Sarana Komunikasi (Sinyal Telepon Seluler).

3. Pernyataan 7: Kondisi Sarana Pendukung Komunikasi (Stop Kontak untuk Pengecasan Telepon Seluler dan Laptop).

4. Pernyataan 11: Identitas karyawan dalam melayani dan membantu wisatawan.

Dimensi responsiveness memiliki dua aspek pelayanan yang perlu untuk ditingkatkan lagi kualitasnya, yaitu:

1. Pernyataan 16: Kecepatan dan ketangguhan dalam menangani keluhan wisatawan

2. Pernyataan 17: Kesesuaian jasa yang diberikan dengan yang dipromosikan

Dimensi assurance memiliki tiga aspek pelayanan yang perlu untuk ditingkatkan lagi kualitasnya, yaitu:

1. Pernyataan 20 : Jaminan keselamatan dalam menggunakan wahana yang disediakan

2. Pernyataan 21: Pelayanan dilakukan sesuai dengan prosedur

3. Pernyataan 22: Pemesanan dengan penuh garansi (pemesanan tempat berkumpul/gazebo)

Dimensi empathy memiliki satu aspek pelayanan yang perlu untuk ditingkatkan lagi kualitasnya, yaitu: Pernyataan 23: Keadilan dalam memberikan pelayanan

Berdasarkan tabel 4.6 nilai skor servsqual untuk kelima dimensi didapatkan hasil dimana nilai Hasil dari penelitian dari 130 responden adalah untuk skor servqual yaitu nilai rata-rata gab tiap dimensi pada pantai melayu adalah tangible (-1,005), reliability (0,969), responsiveness $(-0,938)$ assurance $(-0,883)$, dan 
empathy yaitu (-0,992), dan berdasarkan perhitungan skor servqual hasil perhitungan gab untuk kelima dimensi yaitu selisih antara kenyataan dan harapan > -1 yang berarti puas. Dimensi yang harus ditingkatkan adalah dimensi tangible.

\subsubsection{Hasil Analisis IPA (Importance} Performance Analysis)

Importance Performance Analysis (IPA) adalah alat analisis yang digunakan untuk menganalisis tingkat presepsi dan harapan untuk mengetahui pernyataan yang dinilai masih rendah kinerjanya dan harus ditingkatkan serta pernyataan mana dari 25 pernyataan kualitas pelayanan yang kinerjanya sudah dinilai baik dan harus dipertahankan. Berikut ini hasil penghitungan nilai rata-rata tingkat presepsi dan harapan di pantai vio-vio, pantai mirota dan pantai melayu

\section{Pantai Vio-Vio}

Setiap pernyataan dari kuesioner yang telah dibagikan di kelompokkan berdasarkan analisa IPA yaitu mengelompokkan setiap pernyataan dalam pembagian kuadran, dapat dilihat dari gambar 4.8 berikut:

Tabel 4.8 Perhitungan Perhitungan Posisi

Kuadran pernyataan Pantai Vio-Vio

\begin{tabular}{|c|c|c|c|c|}
\hline Dimensi & $\begin{array}{c}\text { Buti } \\
\mathbf{r}\end{array}$ & $\begin{array}{c}\bar{X} \text { presep } \\
\text { si }\end{array}$ & $\begin{array}{c}\bar{X} \\
\text { harapa } \\
n\end{array}$ & $\begin{array}{c}\text { Kuadra } \\
n\end{array}$ \\
\hline \multirow{11}{*}{ x1 (tangible) } & 1 & 3,60 & 4,15 & IV \\
\hline & 2 & 3,93 & 4,24 & II \\
\hline & 3 & 3,19 & 4,18 & III \\
\hline & 4 & 3,45 & 4,37 & II \\
\hline & 5 & 2,95 & 4,13 & III \\
\hline & 6 & 2,24 & 4,12 & III \\
\hline & 7 & 2,44 & 4,21 & III \\
\hline & 8 & 3,52 & 4,27 & II \\
\hline & 9 & 3,28 & 4,18 & IV \\
\hline & 10 & 3,62 & 4,21 & IV \\
\hline & 11 & 2,88 & 4,22 & III \\
\hline \multirow{4}{*}{ x2 (reliability) } & 12 & 3,19 & 4,20 & III \\
\hline & 13 & 3,22 & 4,38 & $\mathrm{I}$ \\
\hline & 14 & 3,10 & 4,27 & $\mathrm{I}$ \\
\hline & 15 & 3,68 & 4,20 & IV \\
\hline \multirow{3}{*}{$\begin{array}{c}\mathrm{x3} \\
\text { (responsivene } \\
\text { ss) }\end{array}$} & 16 & 3,18 & 4,32 & $\mathrm{I}$ \\
\hline & 17 & 3,19 & 4,28 & $\mathrm{I}$ \\
\hline & 18 & 3,31 & 4,32 & II \\
\hline \multirow{4}{*}{$\begin{array}{c}\mathrm{x4} \\
\text { (assurance) }\end{array}$} & 19 & 3,68 & 4,18 & IV \\
\hline & 20 & 3,22 & 4,22 & III \\
\hline & 21 & 3,27 & 4,28 & II \\
\hline & 22 & 3,05 & 4,18 & III \\
\hline
\end{tabular}

\begin{tabular}{lrrrr}
\hline \multirow{3}{*}{$\mathbf{x}$ (emphaty) } & 23 & 3,18 & 4,26 & I \\
\cline { 2 - 5 } & 24 & 3,38 & 4,23 & IV \\
\cline { 2 - 5 } & 25 & 3,32 & 4,30 & II \\
\hline
\end{tabular}

Sumber: Pengolahan Data

Berdasarkan hasil perhitungan dari 25 pernyataan yang ada, seluruh pernyataan memiliki nilai rata-rata harapan yang lebih besar dibandingkan nilai rata-rata presepsi.

Setelah mengetahui nilai rata-rata dari tiap atribut tersebut, selanjutnya memasukan ratarata tingkat presepsi dan rata-rata harapan tiap atribut ke dalam diagram katresius. Diagram ini memiliki 4 bagian kuadran yang digunakan untuk menggambarkan posisi dari 25 atribut kualitas layanan.

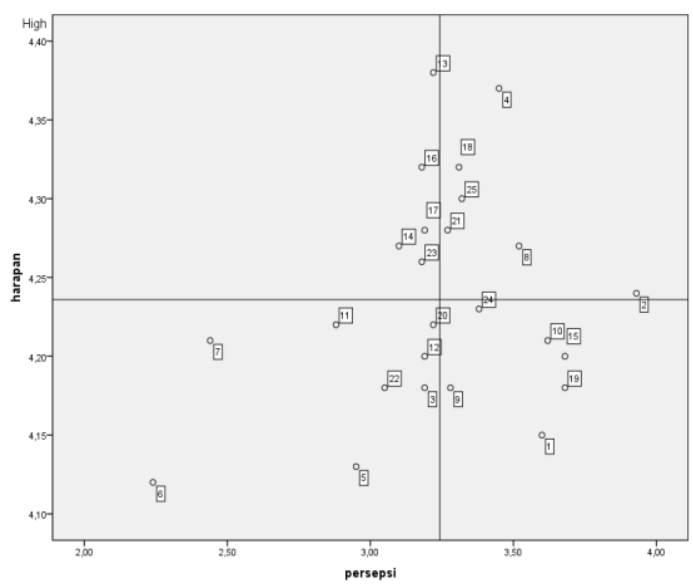

Gambar 4.1 Diagram Kartesius analisis IPA

Berdasarkan gambar 4.1 dapat dilihat dari 25 pernyataan tentang kualitas pelayanan di pantai vio-vio yang perlu ditingkatkan adalah pada yaitu dimensi reliability, responsiviness dan empathy.

\section{Pantai Melayu}

Tabel 4.9. Perhitungan Tingkat Kepuasan Konsumen Per Atribut

\begin{tabular}{|c|c|c|c|c|c|}
\hline Dimensi & $\begin{array}{c}\text { But } \\
\text { ir }\end{array}$ & $\begin{array}{c}\bar{X} \text { perse } \\
\text { psi }\end{array}$ & $\begin{array}{c}\bar{X} \text { hara } \\
\text { pan }\end{array}$ & $\begin{array}{c}G a \\
p\end{array}$ & $\begin{array}{c}\text { Kudr } \\
\text { an }\end{array}$ \\
\hline \multirow{4}{*}{$\begin{array}{c}\mathbf{x 1} \\
(\text { tangible })\end{array}$} & 1 & 3,48 & 4,23 & $\begin{array}{c}- \\
0,7 \\
5\end{array}$ & IV \\
\hline & 2 & 3,53 & 4,28 & $\begin{array}{c}- \\
0,7 \\
5\end{array}$ & II \\
\hline & 3 & 3,18 & 4,40 & $\begin{array}{c}- \\
1,2 \\
2\end{array}$ & I \\
\hline & 4 & 3,30 & 4,17 & $\begin{array}{c}- \\
0,8 \\
7\end{array}$ & IV \\
\hline
\end{tabular}




\begin{tabular}{|c|c|c|c|c|c|}
\hline & 5 & 3,33 & 4,22 & $\begin{array}{c}- \\
0,8 \\
9\end{array}$ & IV \\
\hline & 6 & 2,74 & 4,22 & $\begin{array}{c}- \\
1,4 \\
8 \\
\end{array}$ & III \\
\hline & 7 & 2,77 & 4,27 & $\begin{array}{c}- \\
1,5 \\
0\end{array}$ & I \\
\hline & 8 & 3,54 & 4,09 & $\begin{array}{c}- \\
0,5 \\
5\end{array}$ & IV \\
\hline & 9 & 3,34 & 4,22 & $\begin{array}{c}- \\
0,8 \\
8\end{array}$ & IV \\
\hline & 10 & 3,48 & 4,32 & $\begin{array}{c}- \\
0,8 \\
4\end{array}$ & II \\
\hline & 11 & 2,90 & 4,21 & $\begin{array}{c}- \\
1,3 \\
1\end{array}$ & III \\
\hline \multirow{4}{*}{$\begin{array}{c}\mathrm{x} 2 \\
\text { (reliability) }\end{array}$} & 12 & 3,21 & 4,15 & $\begin{array}{c}- \\
0,9 \\
5 \\
\end{array}$ & III \\
\hline & 13 & 3,26 & 4,22 & $\begin{array}{c}- \\
0,9 \\
6\end{array}$ & III \\
\hline & 14 & 3,22 & 4,20 & $\begin{array}{c}- \\
0,9 \\
8 \\
\end{array}$ & III \\
\hline & 15 & 3,58 & 4,23 & $\begin{array}{c}- \\
0,6 \\
5\end{array}$ & IV \\
\hline \multirow{3}{*}{$\begin{array}{c}\mathrm{x3} \\
\text { (responsive } \\
\text { ness) }\end{array}$} & 16 & 3,21 & 4,25 & $\begin{array}{c}- \\
1,0 \\
4 \\
\end{array}$ & III \\
\hline & 17 & 3,25 & 4,26 & $\begin{array}{c}- \\
1,0 \\
2 \\
\end{array}$ & I \\
\hline & 18 & 3,34 & 4,26 & $\begin{array}{c}- \\
0,9 \\
2 \\
\end{array}$ & II \\
\hline \multirow{4}{*}{$\begin{array}{c}\mathrm{x} 4 \\
\text { (assurance) }\end{array}$} & 19 & 3,56 & 4,26 & $\begin{array}{c}- \\
0,7 \\
0 \\
\end{array}$ & II \\
\hline & 20 & 3,27 & 4,32 & $\begin{array}{c}- \\
1,0 \\
5 \\
\end{array}$ & I \\
\hline & 21 & 3,32 & 4,32 & $\begin{array}{c}- \\
1,0 \\
1 \\
\end{array}$ & II \\
\hline & 22 & 3,28 & 4,40 & $\begin{array}{c}- \\
1,1 \\
2\end{array}$ & I \\
\hline \multirow{2}{*}{$\begin{array}{c}\mathrm{x} 5 \\
\text { (emphaty) }\end{array}$} & 23 & 3,27 & 4,27 & $\begin{array}{c}- \\
1,0 \\
0 \\
\end{array}$ & I \\
\hline & 24 & 3,33 & 4,26 & $\begin{array}{c}- \\
0,9 \\
3\end{array}$ & II \\
\hline
\end{tabular}

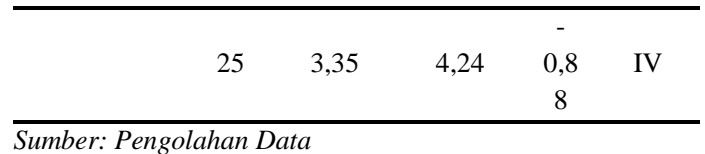

Sumber: Pengolahan Data

Berdasarkan gambar 4.2 dapat dilihat dari 25 pernyataan tentang kualitas pelayanan di pantai Melayu adalah tangible, responsiviness dan empathy.

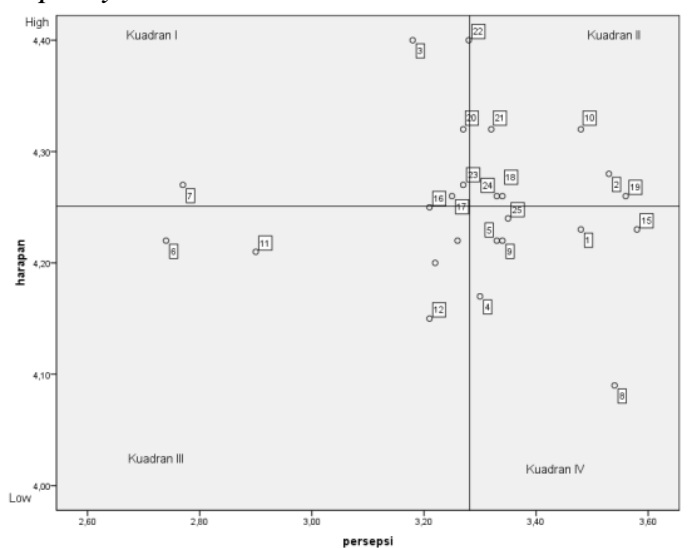

Gambar 4.2 Diagram Kartesius analisis IPA

\section{Kesimpulan}

Hasil dari penelitian dari 130 responden adalah untuk skor servqual yaitu nilai rata-rata gab tiap dimensi pada pantai vio adalah tangible $(-1,005)$, reliability $(0,969)$, responsiveness $(-0,938)$ assurance (-0,883), dan empathy yaitu (-0,992), sedangakan pantai melayu adalah tangible ($1,005)$, reliability $(0,969)$, responsiveness ($0,938)$ assurance $(-0,883)$, dan empathy yaitu (0,992), dan berdasarkan perhitungan skor servqual hasil perhitungan gab untuk kelima dimensi yaitu selisih antara kenyataan dan harapan > -1 yang berarti puas. Analisa IPA pada pantai vio-vio yang perlu ditingkatkan adalah pada kuadran I yaitu dimensi reliability, responsiviness dan empathy sedangkan pada pantai melayu adalah tangible, responsiviness dan empathy.

\section{Daftar Referensi}

Andajani, K . 2017. Pengembangan Industri Pariwisata Dan Ketahanan Ekonomi Nasional. Seminar Nasioanl dan Call of Paper (pp. 52-65). Feb Unikama. 
Arlina, R. Purwanti, E. Y., (2013). Analisis Penerimaan Daerah Dari Industri Pariwisata Di Provinsi DKI Jakarta dan Faktor-Faktor Yang Mempengaruhinya. Diponegoro Journal of Economics. 1(3), 114.

Badan Pusat Statistik Kota Batam, 2017. Kota Batam Dalam Angka 2017. BPS Kota Batam.

Sutanta. 2010. Faktor-Faktor Penyebab Tidak Berkembangnya kawasan IndustriNguter Kabupaten Sukoharjo. Ringkasan Tesis. Program Pascasarjana Magister Teknik Pembangunan Wilayah Dan Kota. Semarang.Universitas Diponegoro.

Wijaya, T. (2018). Manajemen Kualitas Jasa Edisi 2. Jakarta: Indeks.

Yuliani (2013), Strategi Komunikasi Dinas Kebudayaan Pariwisata Dan Kominfo (Disbudpar) Dalam Meningkatkan Kunjungan Wisatawan Di Desa Pampang Kota Samarinda, Jurnal llmu Komunikasi 1(3), 450-464. 